\title{
SOBRE A ESCOLA COMO ESPAÇO DE PRECONCEITOS EM REPRESENTAÇÕES NO GÊNERO REPORTAGEM
}

\author{
Nádia Dolores Fernandes Biavati* \\ Dulcinéa Silva Jerônimo*
}

RESUMO: Neste artigo, apresenta-se uma análise, destacando algumas repercussões possíveis da reportagem intitulada "Vamos combater o preconceito?" publicada na Edição 318 da revista Nova Escola. Cumprimos nosso intento à luz da Teoria das Representações Sociais de Moscovici (1978, 1981, 1984, 1988, 2003) e da Linguística Aplicada enquanto ciência social de estudos da linguagem, especialmente tratando o caráter interdisciplinar das reflexões de Moita Lopes (2006). Os objetivos são a identificação das representações sociais que perpassam os discursos dos entrevistados representados, bem como a análise dos discursos das classes hegemônicas presentes na reportagem. Desse modo, os procedimentos metodológicos utilizados constituem-se na identificação e na análise dos sujeitos em seus papéis sociais e dos discursos enunciados por eles a partir do gênero textual reportagem. Enfim, os papéis sociais indiciam modos de representar a realidade no gênero reportagem, fortalecendo e naturalizando, por vezes, percepções sobre a escola e os sujeitos que são objetos de preconceito.

PALAVRAS-CHAVE: Instituição Escolar; Linguística Aplicada; Preconceito; Representação Social.

\section{Introdução}

A compreensão e problematização do termo cultura constitui uma série de aspectos que se voltam para a constituição da sociedade, bem como para o modo como as práticas

\footnotetext{
* Professora adjunta da Universidade Federal de São João Del-Rei (UFSJ), atuando no Programa de Mestrado em Letras: Teoria Literária e Crítica da Cultura. Doutora em Estudos Linguísticos pela Universidade Federal de Minas Gerais (UFMG).

* Mestranda em Letras - Teoria Literária e Crítica da Culturapela Universidade Federal de São João Del-Rei (UFSJ). 
sociais podem construir determinadas representações direcionadas a valores sociais, estéticos e, até mesmo, econômicos. Nesse sentido, para Carmo (2014), dentre as várias conceituações possíveis do termo, a cultura poderia, ainda, significar a identidade de um povo, circulando elementos simbólicos compartilhados - incluindo valores - capazes de gerar entendimentos referentes às noções de diferenças identidades e lealdades. Por intermédio de tal concepção, é possível dimensionar a multiplicidade de elementos culturais - assim como os modos de percepção das diferenças - que permeiam o ambiente escolar. Acreditamos na visão sobre práticas culturais em que são tomados os sistemas de conhecimentos e crenças que indicam as práticas mais aceitas ou não. Tais elementos podem agir como impulsionadores de preconceitos e exclusão, os quais são capazes de intensificar as assimetrias sociais que ali se encontram, alterando negativamente a representação social das escolas.

Nesse viés, tendo em vista a concepção de Moscovici (2004), segundo a qual os sujeitos constroem e são construídos em relação aos outros por meio da linguagem, o presente artigo visa à identificação das representações sociais que constituem a reportagem “Vamos combater o preconceito?”, manifestações de conhecimentos e crenças sobre como são vistos e retratados os sujeitos excluídos pelo modo de ser ou de agir. Interessa-nos apresentar que papéis sociais circulam na reportagem, indicando práticas culturais representadas sobre a escola e os sujeitos que são objetos de preconceito. Observar as representações que circulam, evocando modos de percepção da realidade nos ajuda a comprovar a ideia de que os preconceitos presentes em ambiente escolar são resultados de valores e ideias compartilhadas pelos grupos, os quais passam a reger as condutas desejáveis ou admitidas nesse contexto, conforme aponta Moscovici (1978). Além disso, serão analisados os discursos das classes hegemônicas que circulam na reportagem, no intuito de identificar a linguagem perpassada por construções sociais que compõem o cenário escolar, acabando por naturalizar e a perpetuar, por vezes, o preconceito. Ao mesmo tempo, atentar para o preconceito possibilita que a sociedade reflita sobre a realidade social. 
A escolha de tais referenciais pautou-se na concepção de que as representações sociais carregam sentidos construídos a partir da arte da conversação os quais, por sua vez, constituem um conjunto de conceitos, proposições e explicações que se originam na vida cotidiana no curso das comunicações interpessoais, conforme postulado por Moscovici (1981). Nesse viés, a necessidade de uma teorização que contemple o campo social, tendo "em vista as interseções de classe social, gênero, sexualidade, etc.", foi fator decisivo na escolha da Linguística Aplicada para fundamentar a análise proposta, observando especialmente as postulações de Moita Lopes (2013), teórico que tem se empenhado em uma discussão sobre uma Linguística Crítica e socialmente comprometida, o que significa, em última instância, ao professor-leitor (No caso da revista Nova Escola), observar as próprias práticas, refletir sobre como elas podem se estruturar ou se desmistificar.

$\mathrm{O}$ artigo encontra-se estruturado em cinco seguintes seções, de modo a garantir os recortes das teorias utilizadas, a contextualização, a análise da materialidade selecionada e as postulações finais acerca do trabalho desenvolvido.

\section{A teoria das representações sociais: funções e conceitos}

Conforme afirma Falcon (2000), o termo "representação" é proveniente do latim "reprasentare" que quer dizer "fazer presente" ou "apresentar novamente" a fim de que, por meio da presença de um objeto, seja possível fazer presente algo ou retratá-lo, alguém ou alguma ideia. Nesse sentido, para Moscovici (2004), a finalidade de todas as representações é tornar familiar algo não familiar. Assim, geralmente, as relações são perpassadas por uma dinâmica de familiarização na qual objetos pessoas e acontecimentos são compreendidos previamente.

Dentro da abordagem de Moscovici, cabe destacar os processos denominados “objetivação" e "ancoragem" que são essencialmente formadores das representações sociais, consolidados ainda na década de 1970 pelo pesquisador.

A objetivação, como se sabe, faz com que se torne real um esquema conceptual, com que se dê uma imagem uma contrapartida material, 
resultado que tem, em primeiro lugar, flexibilidade cognitiva: o estoque de indícios e de significantes que uma pessoa recebe, emite e movimenta no ciclo das infracomunicações pode se tornar superabundante. (MOSCOVICI, 1978, p. 110-111)

Assim, a objetivação ocorre na busca do sujeito por dar forma a algo que não lhe é comum, para que o objeto torne-se concreto ao passo em que deixa de ser abstrato. Cabe ainda acrescentar que tal processo de transformação do abstrato em concreto é perpassado por três fases distintas, conforme explicitado por Jodelet (2005). Na primeira, denominada seleção e contextualização ocorre a construção seletiva da realidade por meio da apropriação do conhecimento a partir de critérios culturais. Na segunda, denominada formação de um núcleo figurativo, a compreensão daquilo que é novo se dá a partir do conhecimento já possuído pelo indivíduo. Finalmente, na naturalização dos elementos de um núcleo figurativo, o conceito torna-se cristalizado, tornando-se elemento da própria realidade.

Por outro lado, a ancoragem relaciona-se ao enraizamento social da representação à integração cognitiva do objeto estando, portanto, associada ao modo de classificar e de rotular. Assim, ambos os processos buscam familiarizar o que é concebido como estranho, construindo novas representações a partir de outras já existentes.

Desse modo, Moscovici postula que:

Ancoragem e objetivação são, pois, maneiras de lidar com a memória. A primeira mantém a memória em movimento e a memória é dirigida para dentro, está sempre colocando e tirando objetos, pessoas e acontecimentos, que ela classifica de acordo com um tipo e os rotula com um nome. A segunda, sendo mais ou menos direcionada para fora (para outros), tira daí conceitos e imagens para juntálos e reproduzi-los no mundo exterior, para fazer as coisas conhecidas a partir do que já é conhecido. (MOSCOVICI, 2011, p. 78)

A “ancoragem” e a "objetivação” trazem à tona a percepção de que as significações que cada sujeito atribui a determinado objeto ou ideia são reflexos de uma série de convenções ligadas à cultura, à comunicação e à linguagem além da inserção sócio econômica, institucional, educacional e ideológica. Desse modo, compreende-se que os preconceitos tornam-se visíveis ao mundo, quando emergem imagens sobre os alunos que são objetos 
de preconceito, provocando e interpelando o olhar do leitor para tal condição de representação desses papéis sociais de "excluídos".

Para Moscovici (2004), as representações possuem duas funções:

1) convencionalizar os objetos, pessoas ou acontecimentos que encontram, de modo a garantir uma forma definitiva e a localizá-los em uma determinada categoria que possa ser, gradativamente, partilhada por um grupo de pessoas. Assim, ainda que alguém ou algo não se enquadre precisamente em determinado modelo, ele é forçado a se adequar a determinados padrões pré-estabelecidos (forma, categoria, realidade);

2) a fusão de uma estrutura fortemente instaurada e da existência de uma tradição capaz de decretar até mesmo o que deve ser pensado faz das representações algo prescritivo que é socialmente imposto por meio de uma força irredutível.

Assim, para Moscovici (2003), tais representações são partilhadas pelas pessoas garantindo a circulação dos sistemas de classificações, das imagens e das descrições, inclusive as científicas. Nesse viés, o sujeito é compreendido como pensador ativo, que não apenas processa e reproduz conhecimento, mas que, sobretudo, constitui e é constituído na interação com o outro em um determinado contexto sócio-histórico. Portanto, a Teoria das Representações Sociais corrobora a existência de uma relação entre o mundo social e a capacidade criativa e transformadora dos sujeitos sociais.

Cabe, ainda, ressaltar que as representações de um sujeito sobre um determinado objeto não são mera reprodução, mas o resultado da percepção dessa realidade capaz de causar rupturas, transformações, resistências e permanências e que, por isso, fornecem referenciais capazes de analisar as dinâmicas presentes nos processos de interpretação e percepção dos fenômenos sociais que envolvem os sujeitos. Portanto, vale a pena pensar sobre como as representações de preconceitos podem atuar no público- leitor- professor, no caso, ao tomar contato com o gênero reportagem que destaque preconceitos que surgem na interação entre os sujeitos escolares. Nessa perspectiva, a marca social das representa- 
ções "remete às condições e ao contexto das quais emergem as representações, às comunicações pelas quais elas circulam, às funções que elas têm na interação com o mundo e com os outros" (JODELET, 1984, p. 362).

\section{Linguística aplicada: construções discursivas no ambiente escolar}

Embora a Linguística Aplicada (doravante LA) já tenha sido interpretada, em seu surgimento, como uma mera aplicação da Linguística no processo de ensino e aprendizagem de línguas, esta é uma ciência pós-moderna que atua na investigação e compreensão da linguagem de diversos grupos sociais. Assim, ao atuar no meio social, trabalhar com vozes marginalizadas e considerar o indivíduo como objeto de pesquisa, é possível conceber a LA como "lugar de ensaio da esperança", conforme proposto por Moita Lopes (2004).

A LA parte da observação de uma prática de linguagem e, a partir dessa mesma prática, teoriza problemas que ali se encontram inseridos. Assim, o linguista aplicado deve situar o seu trabalho no mundo de modo que seja possível problematizar as mudanças presentes no mundo.

Cabe problematizar os modos de produzir conhecimento, de forma a falar diretamente às mudanças avassaladoras que vivemos na vida contemporânea para que seja possível questionar os construtos que vêm orientando a pesquisa na tradição da LA. (MOITA LOPES, 2004, p. 90)

Assim, devido ao caráter disciplinar dinâmico da LA, tal ciência visa a analisar a linguagem concretamente em uso provinda de sujeitos situados nas mais variadas práticas sociais.

Somado a isso, a compreensão das situações de uso da linguagem recebe contribuição de outras disciplinas na LA, conferindo-lhe um aspecto interdisciplinar.

A LA tem como uma de suas tarefas no percurso de uma investigação mediar entre o conhecimento teórico advindo de várias disciplinas (por exemplo, psicologia, educação, linguística, etc.) e o pro- 
blema de uso da linguagem que pretende investigar. O corpo de conhecimento teórico utilizado pelo linguista aplicado vai depender das condições de relevância determinadas pelo problema a ser estudado. (MOITA LOPES, 1996, p. 20-21)

Tendo em vista a concepção do indivíduo como o centro da pesquisa, Moita Lopes (2006) corrobora a ideia de constituição dos sujeitos e do mundo social por meio do discurso, de modo que o posicionamento do indivíduo no mundo e na condição sócio-histórica deva ser concebido como fator determinante para a compreensão da natureza fragmentada, heterogênea e fluida dos sujeitos. Tal concepção é inerente ao objetivo da LA enquanto ciência que visa à problematização da vida social no intuito de compreender as práticas sociais fundamentalmente perpassadas pela linguagem.

Nesse mesmo contexto, Moita Lopes (2006) aponta para a necessidade considerar o posicionamento histórico e social dos sujeitos que constituem o ambiente escolar, ligando-a a construções discursivas sobre o mundo.

No campo da LA na área de ensino/aprendizagem de línguas, tem havido uma tendência contínua a ignorar o fato de que professores e alunos têm corpos nos quais suas classes sociais, sexualidade, gềnero, etnia etc. estão inscritas em posicionamentos discursivos, contemplando somente o sujeito como racional e não como social e histórico, [...] Desse modo, aponto para a importância de reposicionar o sujeito da LA e não para o fim do sujeito (ROSENAU, 1992). (MOITA LOPES, 2006, p. 102)

Os caminhos propostos são de uma Linguística Aplicada Indisciplinar, tomada por ele como uma Linguística Aplicada Mestiça. Nessa perspectiva, propõe-se diálogo com teorias que atravessam o campo das ciências sociais e das humanidades, com intuito de criar inteligibilidade sobre problemas sociais em que a linguagem tem um papel central. Nesse propósito, há uma epistemologia e teorizações que abordem mundo atual e que questionem pressupostos da LA até então. A partir dessa concepção, Moita Lopes (2002) afirma que os participantes discursivos constroem significados a partir da sua interação com outros discursos e por meio de circunstâncias culturais, históricas e institucionais particulares. Assim, a partir desse processo de interação com o interlocutor, as pessoas constroem suas 
identidades sociais ao mesmo tempo em que agem no mundo por intermédio da linguagem. Por essa razão, as construções sociais são dinâmicas.

Nesse viés, é valido corroborar o papel das assimetrias sociais no processo de identidade como construção social, uma vez que "os que ocupam posições de maior poder nas relações assimétricas são, consequentemente, mais aptos a serem produtos de outros seres, por assim dizer" (MOITA LOPES, 2002, p. 34). Assim, os indivíduos que se encontram no topo da pirâmide social tendem a ditar as construções sociais de identidade em função do seu efetivo papel de controle.

Deste modo, a construção das identidades sociais não depende única e exclusivamente dos sujeitos, já que são resultados de práticas discursivas perpassadas por relações de poder ainda que seja possível exercer um papel de resistência contra tais ações.

\section{Metodologia e corpus}

Para Cox Jr. (1993), a diversidade cultural pode ser compreendida como a representação, em um sistema social, de pessoas com afiliações a grupos explicitamente distintos no que diz respeito ao significado cultural. Analogamente, o ambiente escolar é um exemplo de um sistema social composto por vários grupos culturalmente distintos, espaço esse em que deveria ocorrer o pleno respeito a cada diversidade que o constitui. Entretanto, ao se observar a realidade hodierna, constata-se que a escola tem se tornado um ambiente repleto de discriminações e de discursos perpassados pelo ódio e pela aversão, refletindo essa condição da sociedade e, ao mesmo tempo, corroborando discursos esses que se encontram ilustrados no material de análise do presente artigo.

A reportagem da Revista Nova Escola, publicada em 25 de Outubro de 2018, intitulada "Vamos Combater o preconceito?" - a partir do alerta de que "Para a escola ser diversa, de qualidade e para todos, ela precisa combater o ódio e o preconceito" - reuniu uma série de relatos de membros da comunidade escolar que já foram vítimas de discriminação nesse ambiente. Portanto, o que se tem são posições retratadas, representações sobre o preconceito. Ao tomarmos o site da revista, descreve-se que a Associação Nova Escola 
é uma start-up de educação mantida pela Fundação Lemann. O objetivo central da associação, segundo o site, é fortalecer o educador para transformar o Brasil. Assim, as revistas físicas e virtuais NOVA ESCOLA e GESTÃO ESCOLAR, vêm se consolidando como as maiores e mais tradicionais publicações para educadores do país.

Anterior à análise, é necessário expor os aspectos metodológicos que compuseram a prática. O método de análise foi o descritivo-qualitativo. Tendo em vista que o objeto de análise da LA volta-se para a linguagem concretamente em uso por sujeitos social e historicamente situados - em especial aqueles que se encontram na base da pirâmide social foram considerados para a análise os discursos diretos proferidos pelas vítimas de preconceito presentes na reportagem. Cabe acrescentar, ainda, que tais discursos encontram-se entre aspas no corpo da reportagem analisada.

Além disso, são analisadas as representações sociais que perpassam a reportagem à luz da teoria de Serge Moscovici (2011) por meio dos processos de objetivação e ancoragem. Tal integração entre as teorias leva em conta o caráter indisciplinar da LA no intuito de analisar uma questão particular a partir de diferentes abordagens teóricas e de garantir, por meio dessa integração, uma compreensão mais aprofundada de problematizações trazidas pela linguagem.

As análises partirão da materialidade linguística (microanálise) e evoluirão para uma macroanálise, levando em conta as identidades e as representações constitutivas dos s discursos. Considerações metodológicas realizadas, passa-se então para a análise proposta.

\section{Análise - do discurso ao preconceito}

Partindo da concepção de que a LA visa a analisar o uso concreto da linguagem, pôde-se elaborar um quadro em que os são representados os dizeres transcritos, como parte de um conjunto de falas das vítimas de preconceito retratadas no processo de interação, esboçado na reportagem com o intuito de sistematizar análise. As vítimas são nomeadas com nome, sobrenome e idade trazidos na reportagem, além dtrazer citações representativas do preconceito que sofrem, descrito na reportagem. 


\section{Quadro 1: Discursos diretos das vítimas que constituem a reportagem}

"Vamos combater o preconceito?"1

\begin{tabular}{|c|c|}
\hline $\begin{array}{l}\text { "Fui chamado de lixo, como se fosse inferior. } \\
\text { As pessoas deveriam se preocupar com elas } \\
\text { mesmas." }\end{array}$ & \multirow{2}{*}{ Michel Monteiro Fritschy Atie, 11 anos. } \\
\hline $\begin{array}{l}\text { "As pessoas deveriam se preocupar com elas } \\
\text { mesmas, não comigo nem com quanto eu } \\
\text { peso." }\end{array}$ & \\
\hline $\begin{array}{l}\text { "A escola deveria ser um lugar para as pessoas } \\
\text { se sentirem livres. Não de terem medo de ser } \\
\text { quem são." }\end{array}$ & \multirow{3}{*}{ Renato Cardoso, 16 anos. } \\
\hline "Faziam para me provocar e me intimidar." & \\
\hline $\begin{array}{l}\text { "Quando assumi ser transexual, estudava em } \\
\text { uma escola onde o preconceito era velado. } \\
\text { Negros, pessoas com deficiência e imigrantes } \\
\text { também eram discriminados lá." }\end{array}$ & \\
\hline $\begin{array}{l}\text { "Algumas meninas dizem que estamos rou- } \\
\text { bando o emprego dos brasileiros. Fico triste e } \\
\text { com raiva." }\end{array}$ & \multirow{2}{*}{ Alejandra Moreno, 11 anos. } \\
\hline $\begin{array}{l}\text { "Riem de mim se falo coisas erradas em por- } \\
\text { tuguês ou com sotaque. Pensam que não es- } \\
\text { tou ouvindo." }\end{array}$ & \\
\hline $\begin{array}{l}\text { "Não vou ao banheiro na escola. A mãe de } \\
\text { uma aluna reclamou da minha presença no sa- } \\
\text { nitário feminino." }\end{array}$ & Taysa Rafaela da Silva, 15 anos. \\
\hline $\begin{array}{l}\text { "Uma professora me chamou de capitão do } \\
\text { mato. Fico preocupado com os alunos convi- } \\
\text { verem com pessoas como ela." }\end{array}$ & Paulo Rogério Urbano, 46 anos \\
\hline $\begin{array}{l}\text { "Muita gente me chama de homem-bomba na } \\
\text { escola. Dizem que é brincadeira, mas fico cha- } \\
\text { teado." }\end{array}$ & Mhd Lowai Dawabi, 15 anos. \\
\hline $\begin{array}{l}\text { "Um dia abracei um colega autista e disseram } \\
\text { que eu tinha encostado em uma pessoa do- } \\
\text { ente." }\end{array}$ & Leandra Bispo Santos de Jesus, 10 anos. \\
\hline
\end{tabular}

FONTE: autoria própria

\footnotetext{
${ }^{1}$ Cada um dos dizeres transcritos no quadro acima podem ser identificados no texto por meio da numeração correspondente.
} 
Sejam os enunciados (a) e (b) proferidos por Michel Monteiro, de 11 anos, vítima de gordofobia:

(a) "Fui chamado de lixo, como se fosse inferior. As pessoas deveriam se preocupar com elas mesmas."

(b) "As pessoas deveriam se preocupar com elas mesmas, não comigo nem com quanto eu peso."

Em (a), percebe-se que o locutor retrata uma forma de (inter)açãodiscriminatória por meio da voz verbal passiva analítica (fui chamado), que não identifica o autor do que é proferido. Nesse ponto, o locutor aponta para uma representação de si, ao expor uma prática discursiva da qual foi vítima a partir do processo de objetivação. A palavra "lixo" traz consigo uma representação de algo ruim, descartável, impuro, sem valor. Nesse sentido, a padronização cultural de um corpo esbelto com sinônimo de saudável exerce um papel coercivo a partir do qual, aqueles que não se enquadram em tal perfil passam a ser associados ao que há de menos valoroso na sociedade.

Além disso, nesse mesmo enunciado, a ação verbal no futuro do pretérito (deveriam) aponta para uma ação passível de realização, mas que por alguma razão deixou de ser concretizada. Essa mesma construção verbal é replicada em (b) acrescida de outro objeto indireto, o qual indica que "as pessoas devem se preocupar com elas mesmas e não com o quanto ele pesa". Para Abric (1998; 2001), as RS são regidas por um duplo sistema, de modo que um sistema central de determinação estritamente social determina a homogeneidade do grupo, ao passo que um sistema periférico de determinação mais individualizada é capaz de permitir uma heterogeneidade de comportamento. Nesse sentido, ainda que exista uma RS normativa presente no núcleo central, na qual a maioria se preocupa com o peso tido como fora do padrão, há também um elemento periférico excepcional que não deve ser deixado de lado: a necessidade de que esse núcleo central passe a regular essa preocupação. 
(d) "A escola deveria ser um lugar para as pessoas se sentirem livres. Não de terem medo de ser quem são."

(e) "Faziam para me provocar e me intimidar."

(f) "Quando assumi ser transexual, estudava em uma escola onde o preconceito era velado. Negros, pessoas com deficiência e imigrantes também eram discriminados lá."

Os enunciados (d), (e) e (f), acima, foram proferidos por Renato Cardoso, de 16 anos, vítima de transfobia, conforme representação no gênero em questão. Em (d), a forma verbal (deveria), no futuro do pretérito, novamente aponta para algo que não ocorre conforme o esperado. Assim, a RS de uma escola enquanto ambiente que inspira liberdade é desconstruída pelos enunciados (e) e (f), os quais indicam, respectivamente, a intimidação sofrida pelo locutor dentro do ambiente de ensino e outros exemplos de discriminação presentes na escola, a saber o preconceito contra negros, deficientes e imigrantes.

Nesse sentido, se "As identidades sociais construídas na escola podem desempenhar um papel importante na vida dos indivíduos quando se depararem com outras práticas discursivas nas quais suas identidades são re-experenciadas ou reposicionadas" (MOITA LOPES, 2002, p. 38), é possível considerar que tais discursos provindos de um locutor de apenas 16 anos constroem uma representação no mínimo excludente do ambiente escolar. Assim, se a escola não é mais associada a um espaço democrático e de respeito às diferenças, os discursos e as identidades ali construídos acabarão por interferir negativamente em futuras práticas discursivas, tendo em vista a representação social que tem sido construída da escola por essas vozes marginalizadas.

(g) "Algumas meninas dizem que estamos roubando o emprego dos brasileiros. Fico triste e com raiva."

(h) "Riem de mim se falo coisas erradas em português ou com sotaque. Pensam que não estou ouvindo." 
Os enunciados de Alejandra Moreno, venezuelana, de 11 anos, vítima de xenofobia são perpassados por representações sociais distintas. Em (g), o sujeito algumas meninas é agente da ação verbal acusatória de roubo, ao passo que, nesse mesmo excerto, o sujeito desinencial (eu) expõe a tristeza e raiva do locutor por meio do predicativo em que é retratado um modo de vê-la. A acusação sofrida por Alejandra é decorrente de uma RS que permanece cristalizada no meio social, a qual associa o imigrante a um cidadão que vem usurpar direitos dos nativos. Nesse sentido, a intensa imigração venezuelana para o Brasil é resultado do cenário de crise vivenciado naquele país. Essa crise envolve questões políticas, econômicas e sociais, as quais se encontram representadas na linguagem. Desse modo, tal enunciado corrobora a afirmação de Moita Lopes (2002) no que diz respeito à capacidade dos sujeitos construírem significados a partir de circunstâncias culturais e históricas, como ir para outro local e aprender a língua do país de destino.

Cabe também acrescentar que ainda que Sírio Possenti (1996) tenha afirmado que o preconceito linguístico é mais grave e profundo quando dirigido a variedades da mesma língua - tendo em vista que as pessoas tendem a aceitar quem não seja falante do português fale diferente, mas não "permite" a mesma aceitação no que se refere ao falante nativo há, ainda, intrínseca na sociedade, uma RS que tende a associar o poder aos falantes que dominam a norma padrão da língua, de modo que aqueles que utilizam de uma variedade de menor prestígio social tornem-se vítimas desse tipo de preconceito retratado na reportagem.

(i) "Não vou ao banbeiro na escola. A mãe de uma aluna reclamou da minha presença no sanitário feminino."

Já o enunciado (i), acima, trata do preconceito de outra ordem, relativo ao estranhamento ao corpo do outro. Os dizeres (i) são de Taysa Rafaela da Silva, representada como uma menina trans de 15 anos. Taysa é retratada como alunado $8^{\circ}$ ano do Ensino Fundamental. No excerto, há uma sentença negativa e, na sequência, uma declarativa no modo indicativo que aponta para uma RS referente à identidade de gênero, de modo que a mãe não conceba a ideia de um transexual frequentando o mesmo banheiro que a sua filha. 
Muito embora no dia 17 de janeiro de 2018, o Ministro da Educação, Mendonça Filho, tenha homologado a Resolução que autoriza o uso do nome social de travestis e transexuais nos registros escolares da educação básica, questões referentes à identidade de gênero ainda são perpassadas por resistências e polêmicas, principalmente no contexto escolar.

A RS dos transexuais que prevalece na sociedade hodierna ainda é perpassada por preconceito e taxações pejorativas. Nesse sentido, se para Jodelet (2005), o processo de transformação do concreto para o abstrato passa por três etapas distintas (seleção, formação $e$ naturalização), é possível considerar que a mudança da representação dos transexuais encontra-se em formação, tendo em vista que boa parte da sociedade tem construído a sua representação desses indivíduos a partir de critérios culturais e por meio de conhecimentos já possuídos. Todavia, ainda não ocorreu a naturalização do processo, ou seja, a representação dos transexuais enquanto cidadãos detentores de direitos ainda não se tornou um elemento da cristalizado e próprio da realidade vigente.

(j) "Uma professora me chamou de capitão do mato. Fico preocupado com os alunos conviverem com pessoas como ela."

O enunciado (j) foi proferido por Paulo Rogério Urbano de 46 anos. Ele é coordenador pedagógico e foi vítima de racismo no seu ambiente de trabalho. Nesse excerto, o sujeito da primeira ação verbal é uma professora. A representação social que se tem de um professor está associada no caso, a um juízo de valor atribuído por um indivíduo que ocupa uma posição de poder e que detém o conhecimento. Tal posição de poder está diretamente associada à interferência das assimetrias sociais no processo de construção da identidade social apontada por Moita Lopes (2002), tendo em vista que um professor, por seu papel influenciador de liderança, é capaz de ditar determinadas construções em função do seu poder de controle. Por isso, ao apontar que tal fala partiu de uma professora, o locutor evidencia um inconformismo ainda maior, o qual é intensificado pela seguinte afirmação "Fico preocupado com alunos conviverem com pessoas como ela". 
Nesse mesmo enunciado, a representação "capitão do mato" foi construída a um interlocutor que é negro, em um contexto sócio histórico em que um escravo, escolhido para vigiar e perseguir os demais, agia de maneira perversa nos castigos a mando do senhor. Assim, constata-se o processo de ancoragem no qual o enraizamento social dessa função, datada do século XVI, permanece familiarizado no discurso de uma classe hegemônica, rotulando e estigmatizando muitos negros, inclusive dentro do ambiente escolar.

(k) "Muita gente me chama de homem-bomba na escola. Dizem que é brincadeira, mas fico chateado."

O enunciado (k) foi proferido por Mhd Lowai, de 15 anos, vítima de xenofobia. O emprego do sujeito coletivo "muita gente" evidencia a imagem de que a ação sofrida pelo locutor provém de vários sujeitos. Nesse excerto, a objetivação já naturalizado "homem bomba” emerge de uma representação que remete a algo retratado, associado ao destrutivo e a um elemento que oferece riscos. Na sociedade atual, há uma generalização quanto à representação de povos mulçumanos, por exemplo, de modo que a representação do homem bomba permanece direta e erroneamente associada aos refugiados do continente europeu.

Ainda nesse mesmo enunciado, o locutor evidencia, por meio do predicativo do sujeito "chateado", a sensação sentida com as "brincadeiras". Nesse viés, cabe acrescentar a representação da palavra "brincadeira” enquanto algo sadio e prazeroso, representação que se contrapõe com o sentimento de chateação relatado pela vítima.

(1) "Um dia abracei um colega autista e disseram que eu tinha encostado em uma pessoa doente."

No enunciado (1), Leandra Bispo, de 10 anos, portadora da Síndrome de Asperger por meio de verbos no pretérito perfeito relata ações que ocorreram em função de um abraço em uma colega autista. Tendo em mente que para Moscovi (1978) nenhuma mente encontra-se liberta dos efeitos de condicionamentos anteriores que lhe são impostos por suas representações, linguagem ou cultura - fato esse que constitui o processo de ancoragem 
- é possível identificar um juízo de valor culturalmente instaurado que erroneamente associa um autista a uma pessoa doente. Assim, tem-se uma representação social que, embora retrógrada e cientificamente descabida, ainda permanece ancorada no ambiente escolar que, em geral, tende a aceitar crenças e práticas hegemônicas. Desse modo, o ser e estar corriqueiros acabam sendo questionados em práticas e dizeres que indicam o processo preconceituoso exposto na reportagem.

\section{Considerações finais}

O texto aqui apresentado buscou ilustrar, por meio de depoimentos reais, representações sociais que perpassam a linguagem dentro do ambiente escolar e que têm contribuído, direta e amplamente, para a permanência de preconceitos dentro desses ambientes. A identificação dessas representações por meio das postulações de Serge Moscovici possibilitou uma análise mais acurada dos discursos, os quais reafirmam que é por meio da linguagem que se identificam as representações que constituem a sociedade.

A análise, baseada em pressupostos da Linguística aplicada, e voltada para a observação dos discursos, descreve a escola representada na reportagem, repercutindo práticas de preconceitos que resvalam nas práticas escolares. A reportagem retrata, nesse viés, a escola que deveria ser um espaço democrático de respeito e valorização das diferenças, que acaba se tornado um ambiente repleto de discriminações e de discursos perpassados pelo ódio e pela aversão. É nesse contexto de discussão, que as postulações de Moita Lopes (2002) acerca do papel da Linguística Aplicada, enquanto propulsora na busca por alternativas sociais a partir da voz dos que se encontram à margem perpassaram a análise aqui realizada. Tomar os pressupostos dessa abordagem linguística pode ser o caminho de indicar práticas que consideram desmistificar discursos e práticas que tornam, por vezes, a escola preconceituosa e excludente.

Cabe, portanto, ressaltar que as representações de sujeitos sobre um determinado objeto não são mera reprodução, mas o resultado da percepção dessa realidade, fato que 
perpassa o conceito de cultura apontado no início desse trabalho, ainda que o próprio gênero possa reafirmar tal preconceito e naturalizá-lo, por vezes. Assim, uma representação social é capaz de causar rupturas, transformações, resistências e permanências e, por isso, fornece referenciais capazes de apontar formas como podemos e devemos perceber o modo como as realidades são retratadas, analisar as dinâmicas presentes nos processos de interpretação e percepção, tomando as implicaçõesdos fenômenos sociais que envolvem os sujeitos.

\title{
ON SCHOOL AS A SPACE OF PREJUDICE IN REPRESENTATIONS IN GENDER REPORT
}

\begin{abstract}
In this article, we present a discursive analysis of the article entitled "Vamos combater o preconceito?", published in Nova Escola magazine - 318 edition, in light of Moscovici's Theory of Social Representations $(1978,1981,1984,1988,2003)$ and Applied Linguistics, as a social science of interdisciplinary language studies by Moita Lopes (2006). The objectives are the identification of the social representations that permeate the interviewees' speeches, as well as the analysis of the discourses of the hegemonic classes present in the report. Hence, the methodological procedures are constituted by the identification and analysis of the subjects and the discourses enunciated by them from the report.
\end{abstract}

KEYWORDS: Applied Linguistics; Prejudice; School Institution; Social Representation.

\section{REFERÊNCIAS}

ABRIC, Jean-Claude. A abordagem estrutural das representações sociais. In.: Moreira, MASP, \& Oliveira, DC (orgs.). Estudos disciplinares de representações sociais, 1998.

ABRIC, J. C. Prácticas sociales y representaciones. México, Coyoacán. 2001.

CARMO, Cláudio Márcio do. O lugar da cultura nas teorias de base linguistica sistêmico funcional: multimodalidade e produção de sentido na dança-ritual de Oxóssi . Curitiba: Appris, 2014.

COX, Taylor. Cultural diversity in organizations: theory, research \& practice. San Francisco: Berrett Koehler, 1993.

FALCON, Francisco José Calazans. O capitalismo unifica o mundo. O século XX, v. 3, 2000.

JODELET, Denise. Représentation sociale: phénomènes, concept et théorie. Psychologie sociale, v. 2, p. 357-378, 1984. 
MOITA LOPES, L. P. A transdisciplinaridade é possível em linguística aplicada? In: SIGNORINI, I.; CAVALCANTI, M. C. (Orgs.). Linguistica aplicada e transdisciplinaridade. Campinas: Mercado de Letras, 1998, p. 113-128.

MOITA LOPES, L.P. Uma Linguística aplicada mestiça e ideológica: interrogando o campo do linguista aplicado. In: MOITA LOPES, Luis Paulo. (Org.) Por uma Linguística Indisciplinar. São Paulo: Parábola Editorial, 2006. p. 13-43.

MOITA LOPES, L.P. Linguística aplicada e vida contemporânea. Problematização dos construtos que têm orientado a pesquisa. In: MOITA LOPES, Luis Paulo. (Org.) Por uma Linguística Indisciplinar. São Paulo: Parábola Editorial, 2006. p. 85-107

MOSCOVICI, S., 1978. A Representação social da psicanálise. Rio de Janeiro: Zahar.

MOSCOVICI, S., 1988. Notes towards a description of social representations. European Journal of Social Psychology, 18: 211-250.

MOSCOVICI, S., 1989. Des représentations collectives aux représentations sociales. In: JODELET, D. (Org.) Les representations sociales. Paris: Presses Universitaires de France, p. 62-86.

MOSCOVICI, S., Representações sociais: investigação em psicologia social. Petrópolis, RJ: Vozes, 2003.

POSSENTI, Sírio. Porque (não) ensinar gramática na escola. Campinas, SP: Coleção Leituras no Brasil, 1996.

Reportagem analisada:

Disponível em: https://novaescola.org.br/conteudo/12926/somosdiferentessomosiguais. Acesso em 10 de dezembro de 2018

Recebido em: 10/09/2019.

Aprovado em: 30/11/2019. 


\section{Anexos}

\section{nova escola}

Diversidade

\section{Endereço da página:}

https//novaescola.org.br/conteudo/12926/somosdiferentessomosiguais

Publicado em NOVA ESCOLA Ediçăo 318, 25 de Outubro | 2018

\section{Vamos combater o preconceito?}

Histórias de alunos e professores discriminados na escola não podem mais ser aceitas. Para a escola ser diversa, de qualidade e para todos, ela precisa combater o b́dio e o preconceito

Beatriz Vichessi

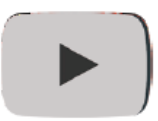

Vídeo: //www.youtube.com/embed/untNXveptVA

"Já fui xingado de baleia e de lixo na escola, como se eu fosse uma pessoa inferior." Essa é só uma das declaraçố de Michel Monteiro Fritschy Atie que deveriam atingir a sociedade, ou seja, cada um de nós, como se fosse um soco no estômago. $O$ garoto de 11 anos é aluno do $5^{\circ}$ ano da Escola Lourenço Castanho, em Săo Paulo, e conta năo ser mais alvo de gordofobia - intolerância a pessoas gordas - e violência dos colegas, mas ainda guarda más lembranças: ficava triste, chorava em casa para encontrar um pouco de alívio e, às vezes, tentava devolver as agressőes, procurando defeitos nos colegas para revidar as ofensas que recebia. Gordofobia, assim como racismo e outras formas de discriminação, é preconceito.

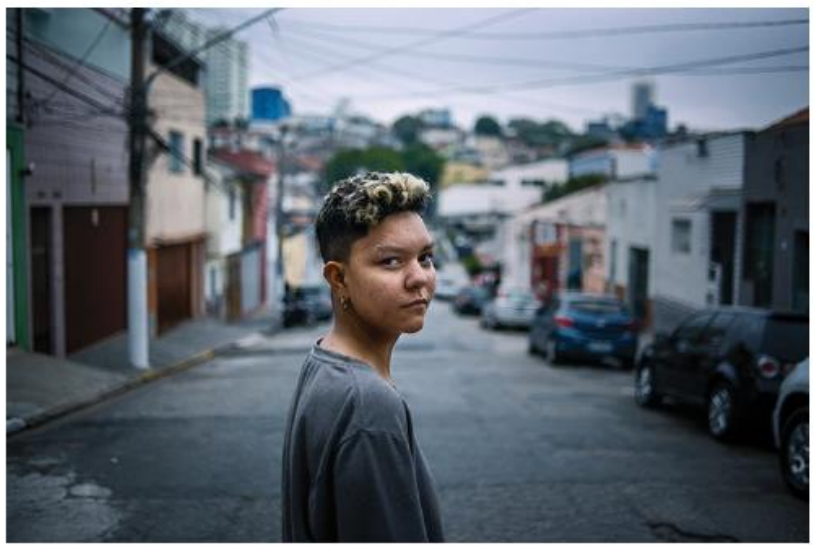

"Quando assumi ser transexual, estudava em uma escola onde o preconceito era velado. Negros, pessoas com deficiência e imigrantes também eram discriminados lá", Renato Cardoso, 16 anos

Crédito: Tuane Fernandes/Nova Escola 
Michel está bem com o seu corpo e encontrou na dança uma forma prazerosa de exibi-lo e gostar mais de si mesmo. Fä de Michael Jackson, ele se apresenta em shows de talentos e em festas. Sua saúde? Vai bem. 0 que o garoto não entende é a raiva que as pessoas podem ter contra quem não tem o corpo magro. "As pessoas deveriam se preocupar com elas mesmas, não comigo nem com quanto eu peso", sugere. Infelizmente, nem sempre isso é o que acontece. "O inferno são os outros", a célebre frase do filósofo francês Jean-Paul Sartre (1905-1980) espelha a natureza da intolerância. "Quando não sou capaz de dialogar com o outro, ele se torna insuportável para mim, vira meu inferno particular", explica Selma Pato Vila, historiadora, psicanalista e gestora da Escola Deep Psicanálise, em São Paulo.

Somos todos tão diferentes uns dos outros em tantos aspectos - não existem duas impressões digitais iguais - e, ao mesmo tempo, tão semelhantes: todos somos seres humanos. Isso só já deveria bastar para que respeito e tolerância fossem imperativos. Mas, definitivamente, estamos longe do ideal e a escola não está imune do cenário de falta de tolerância. Microcosmo da sociedade em que vivemos, ela reproduz padrões sociais, gera e copia preconceitos e, consequentemente, discrimina minorias. "A escola é o primeiro grande palco público, onde a criança se depara com a sociedade e tem de lidar com relaçōes externas", diz Selma. Até então, no ambiente familiar, está circunscrita a um cenário controlado. Os pequenos têm de ser levados a começar a aprender que podem até não gostar de alguém, mas precisam respeitar o direito que cada um tem de ser como é. "É assim que assinamos o contrato social, ganhamos o chamado verniz civilizatório", explica a psicanalista.

De acordo com a pesquisa Viver em São Paulo - Diversidade 2018, da Rede Nossa São Paulo, escolas e faculdades paulistas são o terceiro lugar onde as pessoas presenciam ou vivem situações de preconceito de gênero e de orientação sexual (39\% das respostas). A realidade é bem diferente do que Renato Cardoso, 16 anos, aluno do $3^{\circ}$ ano do Ensino Médio da EE Visconde de Itaúna, em São Paulo, diz ser o ideal: "A escola deveria ser um lugar para as pessoas se sentirem livres. Não de terem medo de ser quem são". Ele é transexual e atualmente frequenta uma escola em que conseguiu ser matriculado usando o nome social. Onde estudava antes, era alvo de discriminação constante. Alguns professores, conta, mesmo sabendo de sua orientação, insistiam em chamá-lo pelo nome civil, que constava nos diários de classe, já que a secretaria se recusou a matriculá-lo usando o nome escolhido por ele. "Faziam para me provocar e me intimidar", lembra Renato.

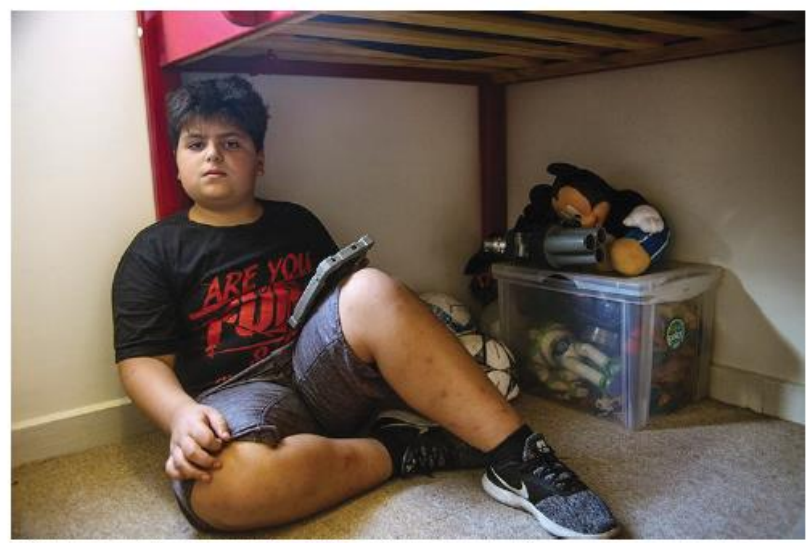

"Fui chamado de lixo, como se fosse inferior. As pessoas deveriam se preocupar com elas mesmas", Michel Monteiro Fritschy Atie, 11 anos Crédito: Tuane Fernandes 


\section{Exemplos aprendidos e ensinados}

Ninguém nasce preconceituoso. Essa é uma ideia que desenvolvemos na infância, principalmente por influência da familia e da escola. O que a criança escuta de familiares e outros adultos de referência, como professores, para ela é correto. "Quando pequenos, não temos como romper com preconceitos ou nos ancorar para defender ideias contrárias ou questionar o que acontece ou é dito ao nosso redor", diz Selma.

O discurso dos adultos pode ser reproduzido de maneira cruel. Alejandra Moreno, 11 anos, é venezuelana e migrou para o Rio de Janeiro, como tantos outros venezuelanos que deixaram a terra natal devastada pela crise. Ela sofre com a xenofobia, a aversão aos estrangeiros ou pessoas de outra cultura, na escola em que estuda. "Algumas meninas dizem que estamos roubando o emprego dos brasileiros. Fico triste e com raiva."

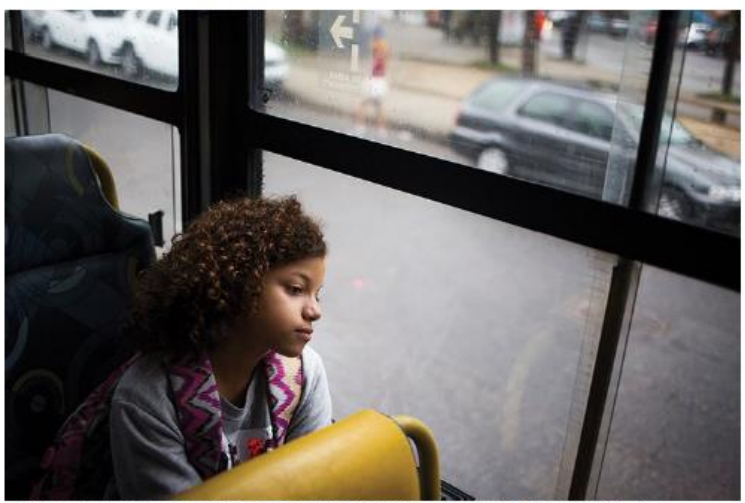

"Riem de mim se falo coisas erradas em português ou com sotaque. Pensam que não estou ouvindo", Alejandra Moreno, 11 anos Crédito: Valda Nogueira

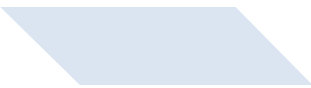

Para garantir espaço para todos, seja na escola, seja na sociedade em geral, não basta promover a inclusão. A palavra-chave é convivio, dando atenção às relaçōes desrespeitosas e destrutivas e fazer mediação para desconstruí-las. "O discurso de que diversidade é algo maravilhoso é insuficiente. A perspectiva pedagógica contemporânea enxerga a diferença como algo que favorece o desenvolvimento humano", diz Rodrigo Hübner Mendes, fundador do Instituto Rodrigo Mendes.

A ideia de escola para todos está registrada na Declaraçăo Universal dos Direitos Humanos, de 1948. Ao visitar a Lei de Diretrizes e Bases para Educação (LDB), de 1996, também é possível encontrar, entre os princípios da Educação, o respeito à liberdade e o apreço à tolerância. E, ainda de acordo com a Constituição de 1988 , o artigo n 227 determina afastar os jovens da discriminação, violência, crueldade e opressão. O Plano Nacional de Educação (PNE), de 2014, também trata da questão, falando da redução das desigualdades e da valorização da diversidade, caminhos imprescindiveis para a equidade. Mais recente, a Base Nacional Comum Curricular (BNCC) trata da perspectiva de educar os jovens para respeitar a diversidade, sem discriminação ou preconceito. Taysa Rafaella da Silva, 15 anos, é uma das alunas que precisa que o documento reverbere de verdade nas escolas. Transexual matriculada no $8^{\circ}$ ano, já foi chamada de "frango" muitas vezes. Ela conta que reclamava para a direçăo, mas as coisas só pioravam. Depois que assumiu a transexualidade, diz que a situação melhorou. Usa maquiagem para ir às aulas, frequenta as aulas de Educação Física junto das meninas. Mas não vai mais ao banheiro da EM Nilo Pereira, em Recife: a mãe de uma aluna reclamou da presença dela no mesmo ambiente usado pelas garotas. 


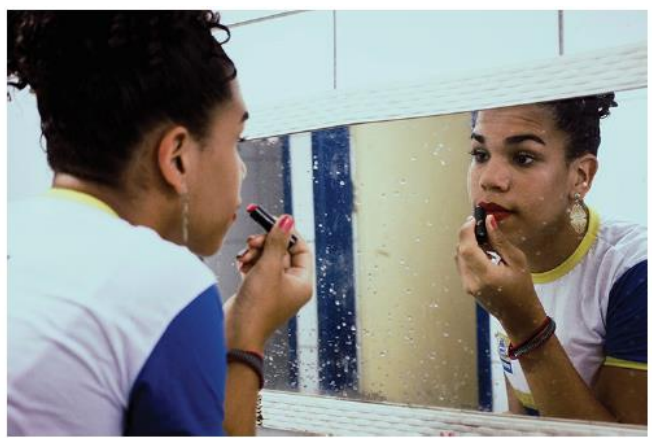

"Não vou ao banheiro na escola. A mãe de uma aluna reclamou da minha presença no sanitário feminino", Taysa Rafaela da Silva, 15 anos.

Crédito: Priscilla Buhr

Histórias como essas são comuns e mostram a necessidade de trabalhar a questão do convivio respeitoso com a diversidade. "A soluçāo não é igualar uns aos outros, e sim batalhar pela equidade. Falar de respeito ao outro, preconceito e discriminaçăo tem de ser um trabalho permanente. A discriminação na escola não acontece com uma ou outra criança, não é pontual. É sistemática - os negros, por exemplo, não são representados no material didático, o racismo permeia o cotidiano deles", afirma Caroline Jango, autora do livro Aqui Tem Racismo (Livraria da Fisica). Rodrigo Mendes atenta para o Projeto Politico Pedagógico (PPP), que tem de acolher as diferenças. Nele devem constar açōes atentas a evidências e conflitos decorrentes da diversidade em sala de aula, cada vez mais heterogênea, "O planejamento deve considerar o coletivo $e$, ao mesmo tempo, atender a individualidade", ressalta. Os educadores também devem se planejar para refletir de forma sistematizada sobre preconceitos. Angela Soligo, psicóloga e docente da Faculdade de Educação da Universidade Estadual de Campinas (Unicamp), explica que eles mesmos (como quaiquer outra pessoa) carregam os seus, que aparecem na forma de segregação, conflitos, ofensas e no jeito com que lidam com os alunos e com os próprios colegas.

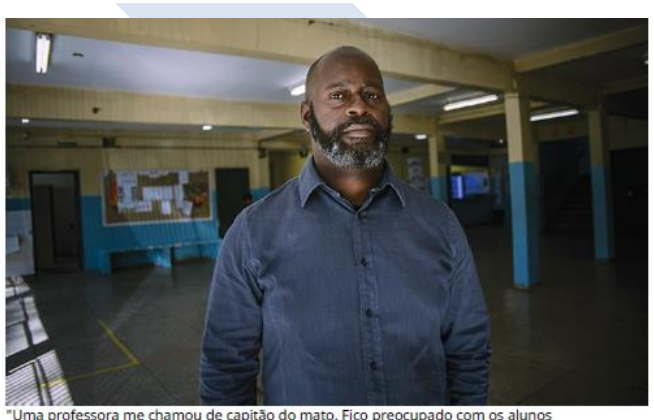

Uma professora me chamou de capitão do mato. Fico preocupado com os alunos

conviverem com pessoas como ela", Paulo Rogério Urbano, 46 anos.

Crédito: Tuane Fernandes

Será que vocé também não reproduz preconceitos sem perceber ao inferiorizar alunos pobres e negros, infantilizar ou ignorar os que têm alguma deficiência e estereotipar imigrantes e refugiados? Mhd Lowai Dawabi, 15 anos, é refugiado sírio e sente a xenofobia na pele. Aluno do $8^{\circ}$ ano do CE Presidente Costa e Silva, em Foz do Iguaçu (PR), está há dois anos no Brasil. Apesar de falar bem português, nāo é incluido de verdade. Chamado de homem-bomba pelos colegas, ele conta que um professor reclamou da participação deleem aula. "Esse ai vem de longe e ainda fica fazendo perguntas", resmungou.

A obra Aqui Tem Racismo apresenta uma pesquisa de Caroline Jango que revela que crianças negras, ao serem convidadas para montar uma sala de aula como a delas usando bonecos. colocaram todos os negros sentados no fundo da sala. Indagadas sobre o motivo, disseram ser assim como a professora delas faz. "Questionar os exemplos usados em atividades e no livro didático, como a mulher em posiçăo inferior (dona de casa, secretária etc.) e não de comando, é saudável para aprender a não naturalizar discriminaçōes e repensar como as coisas são e como deveriam ser para o bem-estar de todos", avalia Angela. 


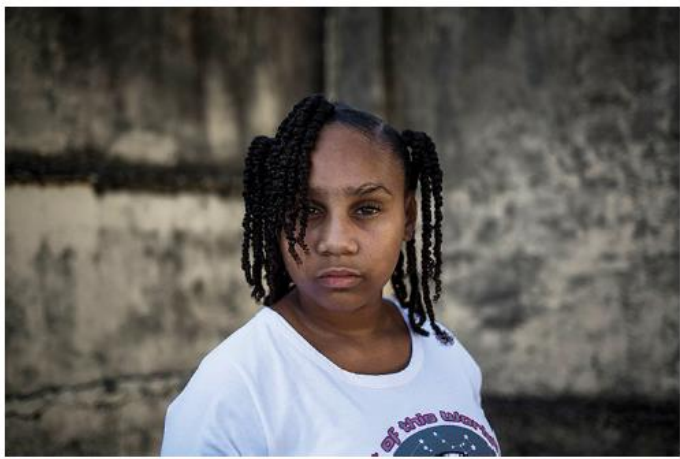

"Um dia abracei um colega autista e disseram que eu tinha encostado em uma pessoa doente", Leandra Bispo Santos de Jesus, 10 anos. Crédito: Pedro Silveira

\section{Não é normal}

Ao discriminar o outro, o preconceituoso age como se existisse um padrão de normalidade. Essa tentativa de dividir as pessoas entre normais e anormais está associadas a um ciência chamada eugenia, que busca definir seres humanos com o melhor patrimônio genético - e que já serviu de justificativa para genocídios, escravidāo e colonização.

De acordo com a antropóloga Isabela Oliveira Kalil, da Fundaçăo Escola de Sociologia e Politica de São Paulo, a construção da diferença é intrínseca ao ser humano. É comum a todas sociedades classificar e hierarquizar pessoas e coisas. Porém, o que é feito disso pode ou não resultar em discriminaçăo e preconceito. "A construçăo da diferença é universal, o preconceito, não", ela explica. Embora vivamos com a sensação de que existe um suposto padrão de normalidade, é preciso depurar o pensamento: nada tem caracteristica neutra a ponto de ser considerado normal. Somos todos diferentes em relação a alguma coisa.

Leandra Bispo Santos de Jesus, 10 anos, é aluna do $4^{\circ}$ ano da EM Nossa Senhora dos Anjo, em Salvador. Ela tem sindrome de Asperger e dá um show quando o assunto é empatia. "Eu aceito como eu sou e como os outros são", fala. Leandra sabe quanto a falta de empatia dos colegas custa caro no dia a dia. Certa vez, na escola, abraçou um colega autista e teve de ouvir dos colegas que tinha encostado em uma pessoa doente.

\section{COMO LIDAR COM O PRECONCEITO?}

Enfrentar a discriminação requer estratégia e formação. Punir nunca é a melhor saída

\section{Presenciei a atitude preconceituosa de um aluno. E agora?}

"Se a escola realiza assembleias, esse pode ser um bom espaço para discutir o fato - não as pessoas envolvidas : dando destaque aos valores que norteiam a boa relação entre as pessoas e repudiando o preconceito", orienta Telma Vinha. Vítima e protagonista não devem ser culpabilizados, já que ambos são frutos das relações sociais, segundo Eliane Cavalleiro no livro Do Silêncio do Lar ao Silêncio Escolar: Racismo, Preconceito e

Discriminação na Educação Infantil. Também é possivel trabalhar com mediação, colocando a situação ocorrida para ser analisada sob diferentes ângulos e falando dos sentimentos de ambas as partes. "Nesse caso, a ação termina com a reparação do conflito, seja por meio da mediação de alguém ou da organização de círculos restaurativos", diz Telma. Obrigar o preconceituoso a pedir desculpas de nada adianta se não for aberta uma linha de diálogo para que ele compreenda o que o colega sentiu. É necessário afirmar que não será 
admitida na escola nenhuma manifestação preconceituosa.

\section{A escola deve fazer projetos especiais para combater o preconceito?}

Trabalhar com o desenvolvimento de projetos pontuais pode até ser válido, desde que os adultos da escola atuem no dia a dia em favor dos princípios de respeito ao próximo e da valorização da diversidade, fazendo com que o discurso deles esteja visivelmente presente nas atitudes. Livros com histórias de personagens e que tratam de preconceito, discriminação, diversidade e inclusão também são ótimos materiais a ser explorados em sala, devem estar sempre à disposição dos alunos - não só quando alguma situação acontece. A postura combativa e a proposição de reflexōes precisam acontecer desde a Educação Infantil, com intencionalidade de educar para o respeito. Ou seja, para explorar questōes tão delicadas, não funciona restringir a conversa a datas especiais. Transformar o sujeito (o gordinho, o negro, o autista) em tema de aula, como se ele fosse um item do curriculo, também não é um bom caminho, pois provoca constrangimentos, de acordo com Maria da Paz, assessora e formadora de professores em Educação e direitos humanos e membro da equipe do Instituto Vladimir Herzog, em São Paulo.

Como agir quando pais de um aluno que foi discriminado pedem uma atitude da escola?

Explique a eles que os envolvidos serão chamados para conversar e que a escola vai ajudar os dois, já que o propósito é combater o preconceito, jamais punir o preconceituoso. Também vale convidar os pais do agressor para conversar. Conte a eles o ocorrido e peça que apoiem a escola. Esclareça que não é natural que crianças ajam de forma cruel, desrespeitosa "só porque são pequenas". Se o fazem é porque aprenderam de alguma forma em casa, na escola, por causa de algo falado ou por conta de uma atitude que presenciaram. 